TITLE:

The Validity of Skeletochronology in Estimating Ages of Japanese Clouded Salamander, Hynobius nebulosus (Amphibia, Caudata)

$\operatorname{AUTHOR}(S)$ :

Matsuki, Takashi; Matsui, Masafumi

CITATION:

Matsuki, Takashi ... [et al]. The Validity of Skeletochronology in Estimating Ages of Japanese Clouded Salamander, Hynobius nebulosus (Amphibia, Caudata). Current Herpetology 2009, 28(2): 41-48

ISSUE DATE:

2009-12

URL:

http://hdl.handle.net/2433/216835

RIGHT:

(C) 2009 by The Herpetological Society of Japan 


\title{
The Validity of Skeletochronology in Estimating Ages of Japanese Clouded Salamander, Hynobius nebulosus (Amphibia, Caudata)
}

\author{
TAKASHI MATSUKI AND MASAFUMI MATSUI* \\ Graduate School of Human and Environmental Studies, Kyoto University, Yoshida \\ Nihonmatsu-cho, Sakyo-ku, Kyoto 606-8501, JAPAN
}

\begin{abstract}
We assessed the accuracy of skeletochronology in estimating ages of Japanese clouded salamanders (Hynobius nebulosus) using the individuals whose ages (1-4 yr) are known by their cohort markings and the individuals that were consecutively captured at intervals of 4-7 yr. Skeletochronology correctly estimated the actual ages of $87.5 \%$ of individuals with known age. The errors in estimation ranged from -1 to $+1 \mathrm{yr}$ with an average of $0.03 \pm 0.11$ (2SE) yr. In the consecutively captured samples, $77.3 \%$ of individuals were correctly estimated to age and the errors ranged from -1 to $+1 \mathrm{yr}$ with an average of $-0.14 \pm 0.20 \mathrm{yr}$. Errors seem to be caused by either the timing of sampling bones or a rapprochement of the bone. However, our results demonstrate that skeletochronology is a valid tool for estimating individual age of $\boldsymbol{H}$. nebulosus studied, with high accuracy and low degree of errors as a whole.
\end{abstract}

Key words: Age estimation; Hynobius nebulosus; LAGs; Life history;

Skeletochronology

\section{INTRODUCTION}

Information concerning age is very important in understanding life history traits of animals and evaluating the status of populations (e.g., Khonsue et al., 2002). Therefore, several methods have been developed and used for estimating age of animals. Skeletochronology (see Smirina, 1994 and Castanet et al., 2003 for reviews) is one of the methods to determine the age of vertebrates by counting stained layers formed in calcified tissues. This layered structure reflects the seasonal changes

* Corresponding author. Tel/Fax: +81-75-7536846;

E-mail address: fumi@zoo.zool.kyoto-u.ac.jp in the growth rate of animals and consists of wide, lightly stained bands of bone tissue bordered by deeply stained lines of arrested growth (LAGs) (Smirina, 1994). Skeletochronology is considered to be a reliable method in principle (Halliday and Verrell, 1988) and has been widely used to determine age in amphibians including Japanese salamanders (e.g., Misawa and Matsui, 1999; Ento and Matsui, 2002; Kusano et al., 2006; Nishikawa and Matsui, 2008).

However, skeletochronology is not a perfect tool for estimating ages and there are some factors that lead to lower accuracy of this method such as endosteal resorption and rapprochement. Endosteal resorption can remove some of the LAGs already deposited (Castanet 
and Smirina, 1990). Rapprochement is the phenomenon that LAGs, subsequent to the deposition of innermost one, generally exhibit tightly packed arrangement, which makes counting LAGs difficult (Francillon-Vieillot et al., 1990). As a result, some authors have even refuted skeletochronology as a method of age estimation (Eden et al., 2007). Indeed the necessity to confirm the validity of skeletochronology using the individuals of known age has been pointed out. However, as far as we know, only a few studies (e.g., Tejedo et al., 1997; Eden et al., 2007) have attempted to study this problem in amphibians because individuals of known age are not easily available.

The Japanese clouded salamander, Hynobius nebulosus, occurs mainly in the lowlands of western Japan, including the mainland and adjacent small islands (Matsui et al., 2006) and breeds once a year in still waters, such as wetlands, artificial ditches and shallow ponds (Tanabe and Matsui, 1997). Ento and Matsui (2002) have already applied skeletochronology to mark-recaptured individuals and confirmed that LAGs are formed annually over corresponding winters. However, in that study, the intervals between first and second capture of individuals were short (1-2 yr), and individuals of known age were not included. The aim of the present study is to confirm the validity of skeletochronology in the population of $H$. nebulosus using the individuals whose ages (1-4 yr) are known by cohort markings performed at the time of their metamorphosis. We also used individuals that were consecutively captured at intervals of 4-7 yr.

\section{MATERIALS AND METHODS}

The H. nebulosus population studied is the same as that already reported elsewhere (Ento and Matsui, 2002). The study site is located within a green space $\left(2430 \mathrm{~m}^{2}\right)$ with an artificial pond on the campus of Kyoto University, in the city of Kyoto, central Japan $\left(35^{\circ} 08^{\prime} \mathrm{N}\right.$, $135^{\circ} 47^{\prime} \mathrm{E}, 98 \mathrm{~m}$ asl). This feral population introduced from adjacent localities between 1983 and 1991 (Ento and Matsui, 2002) and sporadically studied until 1995, has been continuously surveyed since 1996 with special emphases on the breeding seasons. Salamanders arriving in the pond for breeding are captured by hand, dip nets or drift fencing (Halliday, 1996) and are identified individually. We identified individuals by photographs and toe clipping (Waichman, 1992) in earlier times, but adopted passive integrated transponder (PIT) tags (Camper and Dixon, 1988) in 1998. However, toe clipping is still conducted on some of individuals and removed toes are stored in $10 \%$ formalin solution for skeletochronology.

In this population, salamanders mainly breed from winter (late December) to mid spring (early April) and larvae metamorphose from early summer (early June) to early autumn (late September). Overwintering larvae without metamorphosis are very few, and almost all larvae complete their metamorphosis within the year of hatching. Since 1998, each year specific toes of juveniles just after metamorphosis have been clipped in order to distinguish their cohorts. We first removed only one toe (e.g., the third toe of the left hindlimb in 1998), but soon changed to cut more than one toe (e.g., the third and fifth toes of left hindlimb in 2005) in order to minimize later misidentification possibly caused by natural loss or damaged condition of toes. All animals captured in the breeding seasons have been checked for the presence of cohort marks to determine their year of metamorphosis. In some individuals with cohort marks, an intact toe was removed and stored. Toe samples were obtained at the first encounter with animals at the breeding pond. In the present study, we selected 42 toe samples from individuals with distinct cohort marks for this accuracy assessment. Individuals with any dubious markings were excluded from the analyses. In addition, we used toe samples from 24 individuals whose toes were removed twice with the interval of 4-7 yr to test the accuracy of skeletochronology in estimating the time elapsed between the two captures.

The procedure for cross-section preparation 
basically followed Kusano et al. (1995). Toe samples washed in tap water for about one hour and decalcified in 5\% nitric acid for 15$30 \mathrm{~min}$, were washed again in running water for one night and cross-sectioned (20-24 $\mu \mathrm{m}$ thick) using a cryostat. Cross-sections, stained with Mayer's hematoxylin for 30 min under room temperature, were washed again for $60 \mathrm{~min}$ in tap water. Sections from the central region of the diaphysis were chosen and were mounted in a drop of glycerin on glass slides and covered with cover glasses. On these sections, the number of LAGs was examined under a light microscope at $400 \times$ magnification and photographed. The narrow, concentric and hematoxylinophilic lines formed in the region of periosteal bone were interpreted as LAGs. The innermost line near the marrow cavity, regarded as a metamorphosis line (ML: Ento and Matsui, 2002; Tsiora and Kyriakopoulou-Sklavounou, 2002), was recognized at least partially in seven (17.5\%) of the 40 individuals examined, but was not counted as a LAG.

Because adult individuals participate in breeding just after overwintering, while one LAG is thought to be formed sometime after each winter season (Ento and Matsui, 2002), observed LAGs in the breeding individuals are thought to lack the newest line corresponding to the latest winter they experienced. In individuals with known age, the number of winters they experienced was directly compared with the number of LAGs observed in cross sections. While in individuals captured twice with intervals of 4-7 yr, we calculated the number of summer seasons (growth phase for salamanders) that individuals experienced based on capture records. The actual time intervals and the number of LAGs were compared to assess accuracy of skeletochronology.

\section{RESULTS}

\section{Individuals of known age}

Among the 42 individuals whose ages (14 yr) were known by cohort markings, a total of 40 were successfully aged by skeletochronol-

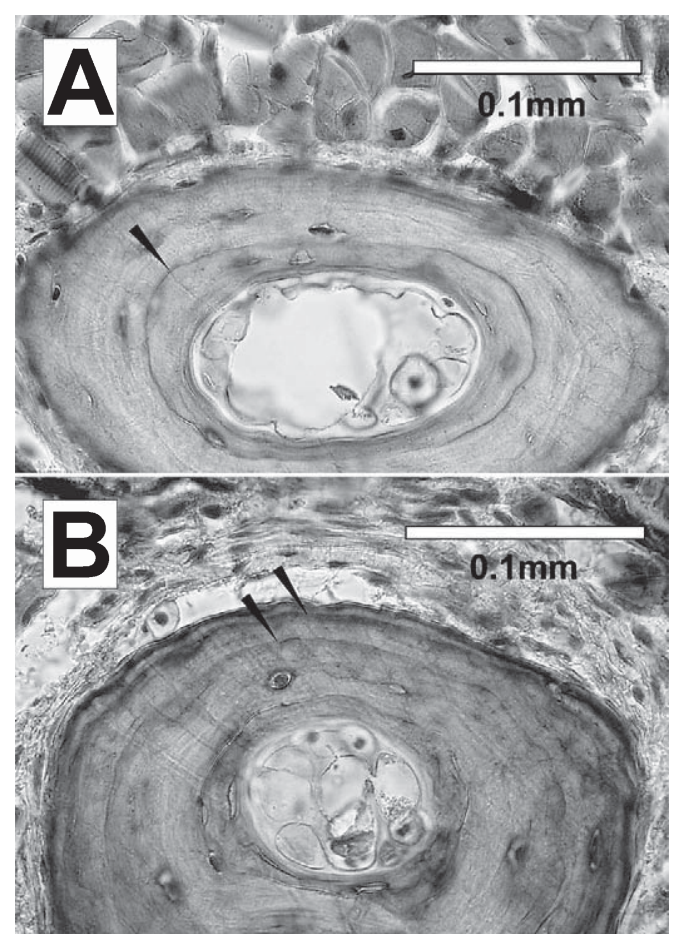

FIG. 1. Cross-sections of digits in (A) 1-yr-old and (B) 2-yr-old individuals of Hynobius nebulosus. Arrows represent LAGs.

ogy (Fig. 1A, B), while the remaining two showed abnormal patterns in their bone histology and were discarded from the analysis. Of these 40 individuals, $35(87.5 \%)$ had the number of LAGs smaller than the number of winters they actually experienced by one (Table 1). Of the remaining five individuals, two had no observable LAGs, while the other three had LAGs whose number was identical with the number of winters they experienced. All these exceptional individuals were captured after their second overwintering, and none of them wintered more than three times.

In the individuals that experienced more than three winters, there was no evidence of resorption or rapprochement increments with the age. The individuals which wintered more than four times and three times were mainly captured in late January and middle February, respectively, while the individuals that over- 
TABLE 1. Result of assessments in individuals of Hynobius nebulosus whose ages are known by cohort marking $(n=40)$.

\begin{tabular}{cccccccc}
\hline Sex & N & Cohort & $\begin{array}{c}\text { Date } \\
\text { recaptured }\end{array}$ & $\begin{array}{c}\text { Actual LAGs } \\
\text { (A) }\end{array}$ & $\begin{array}{c}\text { No. of } \\
\text { wintering (B) }\end{array}$ & $\begin{array}{c}\text { LAGs } \\
\text { expected (C)* }\end{array}$ & A-C \\
\hline Males & 5 & 1998 & Jan-Feb 2001 & 2 & 3 & 2 & 0 \\
& 2 & 2005 & Mar 2008 & 2 & 3 & 2 & 0 \\
& 8 & 2006 & Feb-Mar 2008 & 1 & 2 & 1 & 0 \\
& 2 & 2006 & Mar-Apr 2008 & 2 & 2 & 1 & 1 \\
Females & 1 & 1998 & Jan 2003 & 4 & 5 & 4 & 0 \\
& 6 & 1999 & Jan-Feb 2003 & 3 & 4 & 3 & 0 \\
& 2 & 2000 & Feb-Mar 2003 & 2 & 3 & 2 & 0 \\
& 2 & 2004 & Jan-Mar 2007 & 2 & 3 & 2 & 0 \\
& 1 & 2004 & Mar 2008 & 3 & 4 & 3 & 0 \\
& 1 & 2005 & Mar 2008 & 2 & 3 & 2 & 0 \\
& 7 & 2006 & Mar 2008 & 1 & 2 & 1 & 0 \\
& 1 & 2006 & Mar 2008 & 2 & 2 & 1 & 1 \\
2 & 2006 & Feb-Mar 2008 & 0 & 2 & 1 & -1 \\
\hline
\end{tabular}

* $\mathrm{C}$ equals $\mathrm{B}$ minus $1 \mathrm{yr}$.

wintered twice were captured later, mainly in the middle of March.

\section{Consecutively captured individuals}

Of the total of 24 adults tagged at the first capture and recaptured some years later, we could observe the change in the number of LAGs in 22 individuals (six males and 16 females) (Fig. 2). We failed to obtain adequate bone sections in the remaining two, and omitted them from further analysis. In 17 of 22 individuals $(77.3 \%)$, the number of summer seasons (growth phase for salamanders) that individuals experienced between the two consecutive captures and the number of LAGs (Table 2) were in agreement. The remaining five individuals with discrepancies were all females. Of these, the number of LAGs was smaller than our expectation by one in four individuals, and larger than our expectation by one in one individual. No individuals exhibited a discrepancy of more than two yr. In the four individuals with one LAG fewer than expected, there was no evidence of drastic resorption of bone tissue.

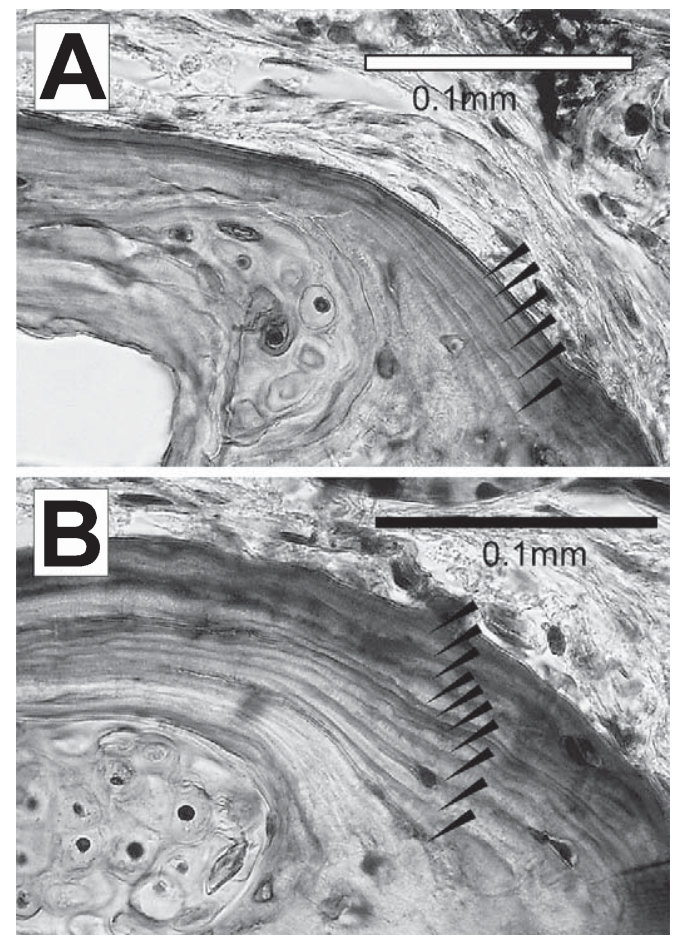

FIG. 2. Cross-sections of digits in an individual of Hynobius nebulosus captured twice (PIT number: 0618-318E), showing (A) six LAGs observed on 23 Jan 2003 and (B) 10 LAGs observed on 9 Feb 2007. 


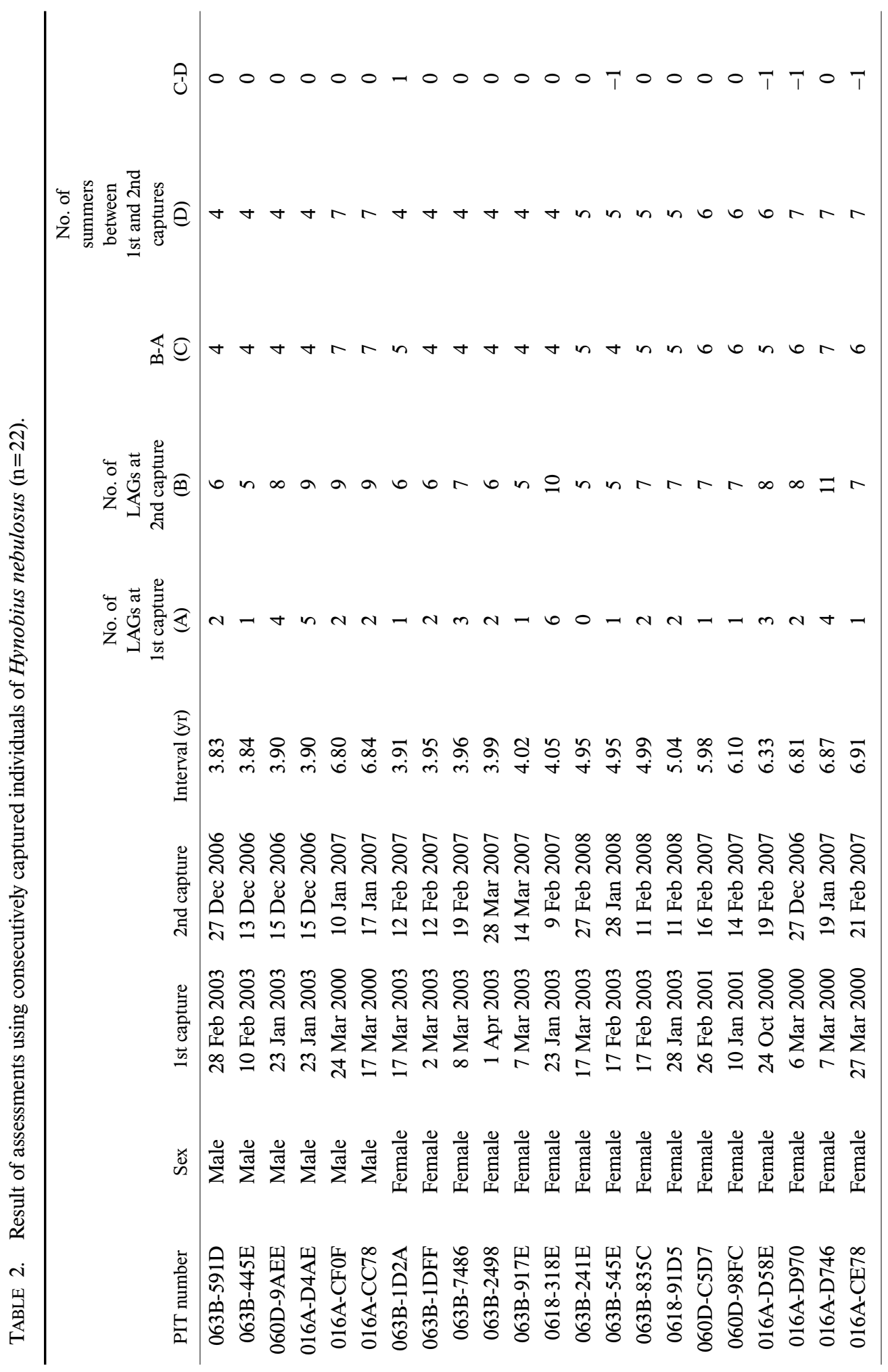




\section{DISCUSSION}

Skeletochronology attempted by Senning (1940) and developed by Smirina (1972) as a technique of estimating ages in amphibians has been applied to many amphibian lineages, and contributed to obtain basic knowledge of their natural history (e.g., age structure, individual growth, and longevity). However, it has been pointed out that interpretation of LAGs should be made carefully in some species. Recently, Eden et al. (2007) applied skeletochronology to a population of an ambystomatid, Ambystoma tigrinum nebulosum, and reported that ages were grossly underestimated especially in older individuals of this species. This finding urges accuracy assessment of skeletochronological analyses, which is, however, not always easily conducted because of the lack of suitable materials. The population of $H$. nebulosus studied here is very ideal for such an investigation, because detailed demographic data have been accumulated over a span of more than $10 \mathrm{yr}$ ( $\mathrm{T}$. Matsuki et al., unpublished data).

In nearly $90 \%$ of the individuals whose ages are known, the number of LAGs observed plus one corresponded to the number of winters they experienced actually. Considering the fact that the newest LAG is not yet formed in the breeding season, just after overwintering (Ento and Matsui, 2002), our results indicate that the ages estimated by skeletochronology are accurate. There was no LAG in two individuals despite having passed through two winter seasons. It is thought that this underestimation is caused by a loss of LAGs through resorption (see below) or difficulty in distinguishing the first LAG from the outer margin of bone due to slow growth just after the winter. On the other hand, possibility of overestimation is suggested in other individuals. The number of winters these individuals experienced coincided with the number of their LAGs. Timing of toe clipping seems to be related to this overestimation. These overestimated individuals most probably participated in breeding activity for the first time just after their second wintering, but their arrival at the pond was later than mid March, about one month later than older individuals which had experienced overwintering three or more times. We consider that the newest LAG is generally formed after late April (Ento and Matsui, 2002), but in some individuals, bone growth may begin before that time with the formation of a new LAG. Because the arrival at the breeding pond, hence timing of toe clipping, was late, the bone would have already started growth and formation of a new LAG in the individuals whose age was overestimated. When these exceptional individuals were included, the difference between actual and estimated ages is only $0.03 \pm 0.11(\overline{\mathrm{x}} \pm 2 \mathrm{SE}) \mathrm{yr}$ among ageknown individuals, and this result strongly supports validity of skeletochronology.

More than three-fourths of the individuals captured twice with long intervals exhibited increments of LAGs coinciding with the number of summers they experienced. As shown above, the LAGs in salamanders begin formation after their overwintering and become clear with the development of the outer layer during the summer seasons when they forage actively. Therefore, the outermost LAG observed in the breeding season (from early winter to spring) should have been formed during the summer season in the previous year. The fact that the number of active seasons experienced agreed with the increment in the number of LAGs demonstrates high accuracy of age estimation by skeletochronology.

In contrast, Eden et al. (2007) doubted the accuracy of skeletochronology in A. tigrinum nebulosum. From the figure they published, it is evident that most of the younger individuals (2-4 yr old) had LAGs smaller than the actual age by one. This might be ascribed to the result of the different timing of LAG formation and sampling, as indicated by our results with $H$. nebulosus, but such a possibility seems very small because Eden et al. (2007) counted the outer perimeter of the bone as a LAG as we did, although irrespective of the nature of samples. In this case, over-, and not under-, estimation is expected, just opposite to 
the actual results. Most probably, the incongruence of actual and estimated ages would have derived from unknown factors related to differences in the life history of the species studied (see below).

Most of the individuals whose ages were wrongly assessed showed LAGs whose increment was smaller than our expectation by one, and posed the risk of underestimation of one year. Because there was no evidence of drastic resorption among these individuals, and their LAGs were tightly arranged, the discrepancy probably derives from rapprochement. Eden et al. (2007) similarly reported underestimation of ages by skeletochronology in A. tigrinum nebulosum, especially in older individuals, and attributed such results to bone resorption and/or rapprochment. However, although individuals of $H$. nebulosus underestimated were old (6-9 yr old, based on the number of LAGs at the first capture), the old age itself does not seem to be related to the discrepancy because the ages of most other individuals similarly as old or older (maximum $=11 \mathrm{yr}$ old) were correctly assessed. Although the reason for one-yr overestimation in another individual is unclear, the timing of toe clipping (see above) or occurrence of double LAGs (FrancillonVieillot et al., 1990; Smirina, 1994; Olgun et al., 2005) may be responsible for this phenomenon. Even though the intervals between two consecutive captures extended over a long time (4-7 yr), underestimation or overestimation of individual ages was rare. The errors in estimations range from -1 to $+1 \mathrm{yr}$, with an average of only $-0.14 \pm 0.20 \mathrm{yr}$.

From all aspects of results obtained here, we conclude that skeletochronology accurately estimates ages of individuals in our $H$. nebulosus population. On the other hand, sufficient knowledge on the life history of the study animals is inevitable for correctly interpreting results obtained by skeletochronology. Indeed, A. tigrinum nebulosum, by which Eden et al. (2007) claimed the accuracy of skeletochronology, is notoriously variable in life history traits (e.g., Petranka, 1998) and the samples used by Eden et al. (2007) actually included both metamorphosed and neotenic individuals. The complex nature of the samples studied also might have led unusual skeletochronological results. Furthermore, Eden et al. (2007) examined individuals of two extreme age classes (2-4 and 13-15 yr old) and did not examine intermediate classes, in which LAGs may exhibit actual ages. Therefore, their conclusion that the number of LAG is an inaccurate estimate of age seems premature.

\section{ACKNOWLEDGMENTS}

The authors thank Y. Misawa and K. Nishikawa for advice about the technique of skeletochronology, and W. Khonsue, K. Ento, T. Sugihara, A. Tominaga, T. Kubota, K. B. Dontchev, Y. Miyagata, Hir. Ito, T. Shimada, Y. Inoue-Watanabe, G. Aoki, N. Yoshikawa, N. Kuraishi, Hid. Ito, A. Hamidy, and K. Eto for collecting samples.

\section{LITERATURE CITED}

CAMPER, J. D. AND DiXON, J. R. 1988. Evaluation of a microchip marking system for amphibians and reptiles. Research Publication 7100-159. Texas Parks and Wildlife Department, Austin, Texas.

CASTANET, J. AND SMIRINA, E. M. 1990. Introduction to the skeletochronological method in amphibians and reptiles. Annales des Sciences Naturelles Zoologie, Paris. Série 13 11: 191-196.

Castanet, J., Francillon-Vieillot, H., De RicQlès, A., AND ZylberberG, L. 2003. The skeletal histology of the Amphibia. p. 15981683. In: H. Heatwole (ed.), Amphibian Biology Vol. 5 Osteology. Surrey Beatty and Sons Pty Ltd., Australia.

EdEn, C. J., Whiteman, H. H., Duobinis-Gray, L., AND WisSINGER, S. A. 2007. Accuracy assessment of skeletochronology in the Arizona tiger salamander (Ambystoma tigrinum nebulosum). Copeia 2007: 471-477.

ENTO, K. AND MATSUI, M. 2002. Estimation of age structure by skeletochronology of a population of Hynobius nebulosus in a breeding season (Amphibia, Urodela). Zoological Science 19: 
241-247.

FranCILlON-VieILlot, H., ARNTZEN, J. W., AND GERAUDIE, J. 1990. Age, growth and longevity of sympatric Triturus cristatus, T. marmoratus and their hybrids (Amphibia, Urodela): a skeletochronological comparison. Journal of Herpetology 24: 13-22.

Halliday, T. R. 1996. Amphibians, p. 278-296. In: W. J. Sutherland (ed.), Ecological Census Techniques. Second Edition. Cambridge University Press, Cambridge, UK.

HALlidAy, T. R. AND VeRRELl, P. A. 1988. Body size and age in amphibians and reptiles. Journal of Herpetology 22: 253-265.

Khonsue, W., MATSUI, M., AND Misawa, Y. 2002. Age determination of Daruma pond frog, Rana porosa brevipoda from Japan towards its conservation (Amphibia: Anura). AmphibiaReptilia 23: 259-268.

Kusano, T., Funuyama, K., AND Miyashita, N. 1995. Age determination of the stream frog, Rana sakuraii, by skeletochronology. Journal of Herpetology 29: 625-628.

Kusano, T., Ueda, T., AND Nakagawa, H. 2006. Body size and age structure of breeding populations of the salamander, Hynobius tokyoensis (Caudata: Hynobiidae). Current Herpetology 25: 71-78.

Matsui, M., Nishikawa, K., Utsunomiya, T., AND TANABE, S. 2006. Geographic allozyme variation in the Japanese clouded salamander, Hynobius nebulosus (Amphibia: Urodela). Biological Journal of the Linnean Society 89: 311-330.

Misawa, Y. AND Matsui, M. 1999. Age determination by skeletochronology of the Japanese salamander Hynobius kimurae (Amphibia, Urodela). Zoological Science 16: 845-851.

NisHiKAWA, K. AND MATSUI, M. 2008. A comparative study on the larval life history in two populations of Hynobius boulengeri from Kyushu,
Japan (Amphibia: Urodela). Current Herpetology 27: 9-22.

Olgun, K., Uzum, N., Avci, A., And Miaud, C. 2005. Age, size and growth of the southern crested newt Triturus karelinii (Strauch 1870) in a population from Bozdag (Western Turkey). Amphibia-Reptilia 26: 223-230.

PetrankA, J. W. 1998. Salamanders of the United States and Canada. Smithsonian Institution Press, Washington and London.

SENNING, W. C. 1940. A study of age determination and growth of Necturus maculosus based on the parasphenoid bone. American Journal of Anatomy 66: 483-495.

SMIRINA, E. M. 1972. Annual layers in bones of Rana temporaria. Zoologicheskii Zhurnal 51: 1529-1534. (in Russian)

SMIRINA, E. M. 1994. Age determination and longevity in amphibians. Gerontology 40: 133146.

TANABE, S. AND Matsui, M. 1997. Hynobius nebulosus. p. 287-291. In: Japan Fisheries Agency (ed.), Basic data for Endangered Wild Aquatic Organisms of Japan (IV). Japan Fisheries Resource Conservation Association, Tokyo. (in Japanese)

Tejedo, M., Reques, R., AND Esteban, M. 1997. Actual and osteochronological estimated age of natterjack toads (Bufo calamita). Herpetological Journal 7: 81-82.

TSIORA, A. AND KYRIAKOPOULOU-SKLAVOUNOU, P. 2002. A skeletochronological study of age and growth in relation to adult size in the water frog Rana epeirotica. Zoology 105: 55-60.

WAICHMAN, A. V. 1992. An alphanumeric code for toe clipping amphibians and reptiles. Herpetological Review 23: 19-21.

Accepted: 25 May 2009 